\title{
Effect of acidic aqueous alcohol solution on template sol-gel synthesis of phosphorescent hexagonal mesoporous silica film nanocomposite
}

\author{
Hendrik O. Lintang ${ }^{1,3 *}$, Kazushi Kinbara ${ }^{2}$ and Takuzo Aida ${ }^{1}$ \\ ${ }^{1}$ Department of Chemistry and Biotechnology, The University of Tokyo, 7-3-1 Hongo, Bunkyo-ku, Tokyo 113-8656, Japan \\ ${ }^{2}$ Institute of Multidisciplinary Research for Advanced Materials (IMRAM), Tohoku University, 2-1-1 Katahira, Aoba-ku, Sendai 980-8577, Japan \\ ${ }^{3}$ Ibnu Sina Institute for Fundamental Science Studies, Universiti Teknologi Malaysia, 81310 UTM Skudai, Johor, Malaysia \\ Received 22 April 2011, Revised 2 May 2011, Accepted 10 May 2011, Available online 28 June 2011
}

\begin{abstract}
Here novel mesoporous silica film nanocomposite with a hexagonal structure is successfully synthesized by using phosphorescent columnar assembly of a trinuclear gold(I) pyrazolate complex bearing amphiphilic side chains $\left[\mathrm{Au}_{3} \mathrm{Pz}_{3}\right]$, formed via a weak $\mathrm{Au}^{\mathrm{I}}-\mathrm{Au}^{\mathrm{I}}$ metallophilic interaction, as a functional template in the sol-gel synthesis. By controlling the molar ratios of alcohol to acid in an acidic aqueous alcohol solution, the sol-gel synthesis of columnar assembled $\left[\mathrm{Au}_{3} \mathrm{Pz}_{3}\right]$ with a silica source can provide highly ordered hexagonal mesoporous silica film composite $\left[\mathrm{Au}_{3} \mathrm{Pz}_{3}\right] /$ silica $\mathrm{hex}_{\text {hex }}$ consisting one-dimensional molecular assembly in the nanoscopic channels. The as-fabricated silica film nanocomposite $\left[\mathrm{Au}_{3} \mathrm{Pz}_{3}\right] / \mathrm{silica}_{\text {hex }}$ with red emission have phosphorescent properties with luminescence emission centered at $693 \mathrm{~nm}\left(\lambda_{\mathrm{ext}}=276 \mathrm{~nm}\right.$; Stokes shift, $\left.\Delta \lambda=417 \mathrm{~nm}\right)$ and lifetime at $7.8 \mu \mathrm{s}\left(\lambda_{\mathrm{ext}}=266\right.$ $\left.\mathrm{nm}, \lambda_{\mathrm{em}}=690 \mathrm{~nm}\right)$.
\end{abstract}

| Hexagonal | Mesoporous | Nanocomposites | Sol-gel | Template |

\section{INTRODUCTION}

Nanocomposite-based on organosiloxane, clay and mesoporous silica materials have been widely used in many fields such as optics, electronics, energy, membranes, catalysts, sensors, and medicine [1]. In particular, immobilization of one-dimensional (1D) nanostructured organic functional groups in the nanoscopic channels of inorganic mesoporous silica with a hexagonal structure have attracted much attention for developing anisotropic optoelectronic materials [2]. Generally, mesoporous silica materials can be functionalized with organosilica precursors by post-synthetic grafting and one-pot sol-gel synthesis methods [3]. However, all of these approaches cannot ensure dense filling of the functional groups inside the silicate nanochannels. In 2001, Aida et al. [4] and Brinker et al. [5] have independently reported a universal strategy for dense filling of the functional groups by using functional amphiphiles of diacetylenic surfactant monomers as a template in the one-pot sol-gel synthesis. The functional templates were not only ordinary polymerizable monomer amphiphiles [4-8], but also 1D columnar assembly of diskshaped amphiphilic molecules such as triphenylene [9], metallophtalocyanine [10], hexaperi-benzocoronene [11], and Pt(II)bipyridine complexes [12].
We have recently demonstrated that mesoporous silica film nanocomposite with a hexagonal structure $\left[\mathrm{Au}_{3} \mathrm{Pz}_{3}\right] /$ silica $_{\text {hex }}$ can be successfully fabricated in the colorless transparent thin film by the template sol-gel synthesis using columnar assembly of $\left[\mathrm{Au}_{3} \mathrm{Pz}_{3}\right]$ [13]. The silicate nanochannels contains only one columnar assembly with a chair-like coordination geometry of polymeric $\left[\mathrm{Au}_{3} \mathrm{Pz}_{3}\right]$ formed by a weak $\mathrm{Au}^{\mathrm{I}}-\mathrm{Au}^{\mathrm{I}}$ metallophilic interaction. When the spin-coated film was allowed to stand at $20^{\circ} \mathrm{C}$ for $5 \mathrm{~h}$ after stepwise heating to $140{ }^{\circ} \mathrm{C}$, the fabricated 1D columnar assemblies in the nanochannels with an interpore distance of $4.1 \mathrm{~nm}$ can perfectly selfrepair from heat-induced structural damage due to a nanoscopic template effect [13]. More recently, we have found that the spin-coated film of $\left[\mathrm{Au}_{3} \mathrm{Pz}_{3}\right] /$ silica hex showed heating effect on self-repairing capability, where the autonomous recovery was perfectly achieved depending on the way of heating; when the hexagonal silica film nanocomposite were heated stepwise from 20 to $140{ }^{\circ} \mathrm{C}$ in $45 \mathrm{~min}$ or directly to $160^{\circ} \mathrm{C}$ in $11 \mathrm{~min}$ [14]. Here we report the systematic studies on the sol-gel synthesis for the fabrication of highly ordered mesoporous silica film nanocomposites with a hexagonal geometry by controlling molar ratios of an acidic aqueous alcohol solution in the self-assembly of $\left[\mathrm{Au}_{3} \mathrm{Pz}_{3}\right]$ with a silica source (Fig. 1). 


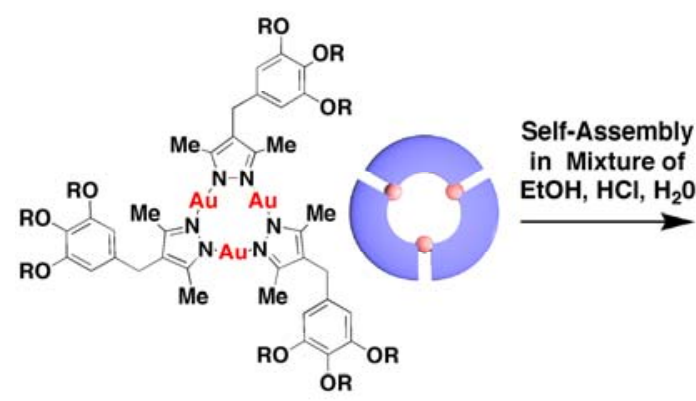

$\left[\mathrm{Au}_{3} \mathrm{Pz}_{3}\right]$

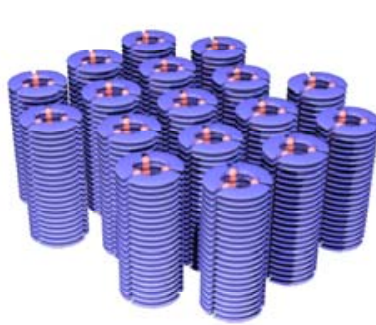

Columnar Assembly
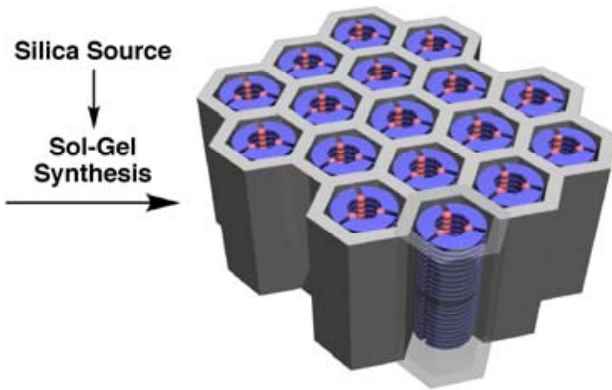

$\left[\mathrm{Au}_{3} \mathrm{Pz}_{3}\right] /$ silica $_{\text {hex }}$

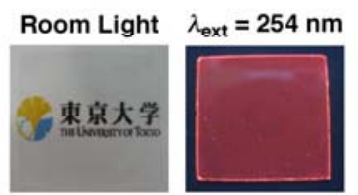

Figure 1: Schematic representation of fabrication of mesoporous silica film nanocomposite $\left[\mathrm{Au}_{3} \mathrm{Pz}_{3}\right] / \mathrm{silica}_{\text {hex }}$ with a hexagonal geometry, templated by columnar assembly of $\left[\mathrm{Au}_{3} \mathrm{Pz}_{3}\right]$ via sol-gel synthesis. Photographs were taken at room temperature under room light and on exposure to ultraviolet light at $254 \mathrm{~nm}$.

\section{EXPERIMENTAL}

\section{$2.1 \quad$ Instruments}

${ }^{1} \mathrm{H}$ and ${ }^{13} \mathrm{C}$ NMR spectra (500 and $125 \mathrm{MHz}$ ) were recorded in $\mathrm{CDCl}_{3}$ on a JEOL model GSX-500 spectrometer, where the chemical shifts were determined with respect to non-deuterated residue $\mathrm{CDCl}_{3}$ at $\delta=7.24$ and $77.0 \mathrm{ppm}$ for ${ }^{1} \mathrm{H}$ and ${ }^{13} \mathrm{C}$ NMR spectroscopy, respectively. Matrix-assisted laser desorption/ionization time-of-flight mass-spectrometry (MALDI-TOF-MS) was performed with dithranol as a matrix on a PerSeptive Biosystems model Voyager-DE spectrometer. Preparative size-exclusion chromatography (SEC) was performed at room temperature on a Japan Analytical Industry model LC-908 recycling preparative HPLC, equipped with a variable-wavelength UV-vis detector, using $\mathrm{CHCl}_{3}$ as an eluent at a flow rate of $3.5 \mathrm{~mL} \mathrm{~min}{ }^{-1}$. Elemental analysis was performed on a Yanaco model CHN CORDER MT-6. Infrared spectra were recorded on a JASCO FTIR-610 spectrophotometer.

The resulting transparent films were characterized by $\mathrm{X}$-ray diffraction (XRD) at room temperature at Rigaku model RINT 2400 diffractometer with $\mathrm{CuK} \alpha$ radiation and a step size $0.02^{\circ}$ at scan speed of $2^{\circ} \mathrm{min}^{-1}$. X-ray photoelectron spectroscopy (XPS) were conducted on a JEOL JPS-9000MC spectrometer with $\operatorname{MgK} \alpha$ radiation $(1253.6 \mathrm{eV})$ and the XPS peaks are internally referenced to the binding energy of $\mathrm{C} 1 \mathrm{~s}$ peak at $284.5 \pm 0.1 \mathrm{eV}$. Emission spectra were recorded on JASCO model FP-6500 spectrometer equipped with a thin film sample folder. Transient emission spectra were measured by pumping the samples with the fourth harmonics of a light from a Nd:YAG laser (HOYA Continuum Satellite I, pulse duration of $10 \mathrm{~ns}$ and repetition of $10 \mathrm{~Hz}$ ), and monitored with a HAMAMATSU Photonics model R3788 photomultiplier lifetime.

\subsection{Synthesis of $\left[\mathrm{Au}_{3} \mathrm{Pz}_{3}\right]$}

Complex $\left[\mathrm{Au}_{3} \mathrm{Pz}_{3}\right]$ was synthesized according to the synthetic protocol reported previously [13]. Typically, to a dry THF $(20 \mathrm{~mL})$ solution of amphiphilic pyrazole ligand (400 mg, $0.35 \mathrm{mmol})$ was added $\left[\mathrm{Au}\left(\mathrm{SMe}_{2}\right)\right] \mathrm{Cl}(103.2 \mathrm{mg}$, $0.35 \mathrm{mmol}$ ), and the resulting mixture was stirred at room temperature for 5 min under $\operatorname{Ar}$ (Scheme 1). To this solution was dropwise added a dry $\mathrm{MeOH}$ solution of $\mathrm{KOH}$

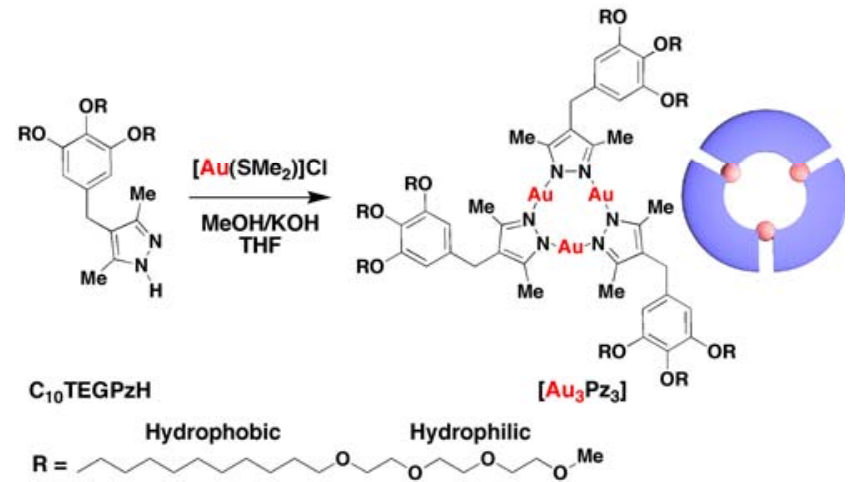

Scheme 1: Synthesis and molecular structure of $\left[\mathrm{Au}_{3} \mathrm{Pz}_{3}\right]$.

(0.26 M, $1.4 \mathrm{~mL})$ using a Schlenk technique, and the resulting mixture was stirred for $12 \mathrm{~h}$ under $\mathrm{Ar}$ at room temperature in the dark condition. The reaction mixture was filtered off from insoluble substances, and the filtrate was evaporated to dryness under reduce pressure at room temperature. The residue was chromatographed on silica gel with AcOEt/MeOH (10:1) as an eluent, where the first fraction was then collected and evaporated to dryness. The residue was subjected to preparative size exclusion chromatography (SEC) with $\mathrm{CHCl}_{3}$ as an eluent, where the 
first fraction was collected, evaporated and freeze-dried from benzene, to give $\left[\mathrm{Au}_{3} \mathrm{Pz}_{3}\right]$ as pale-yellow sticky solid in $70 \%$ yield (325.9 mg) [13]; ${ }^{1} \mathrm{H}$ NMR (500 $\mathrm{MHz}, \mathrm{CDCl}_{3}$, $20^{\circ} \mathrm{C}$ ): $\delta 6.25$ (s, $\left.6 \mathrm{H}, \mathrm{ArH}\right), 3.86$ (t, $18 \mathrm{H}, \mathrm{ArOCH}_{2}$ ), 3.64 (s, $\left.6 \mathrm{H}, \mathrm{ArCH}_{2} \mathrm{C}\right), 3.63-3.52\left(\mathrm{~m}, 108 \mathrm{H}, \mathrm{OCH}_{2} \mathrm{CH}_{2}\right), 3.42$ (t, $\left.18 \mathrm{H}, \mathrm{CH}_{2} \mathrm{O}\right), 3.36\left(\mathrm{~s}, 27 \mathrm{H}, \mathrm{OCH}_{3}\right), 2.14$ (s, $\left.18 \mathrm{H}, \mathrm{py}-\mathrm{CH}_{3}\right)$, $1.72-1.67\left(\mathrm{~m}, 18 \mathrm{H}, \mathrm{ArOCH}_{2} \mathrm{CH}_{2}\right), 1.55-1.53(\mathrm{~m}, 18 \mathrm{H}$, $\mathrm{CH}_{2} \mathrm{CH}_{2} \mathrm{O}$ ), 1.43-1.37 (m, 18H, $\left.\mathrm{ArOCH}_{2} \mathrm{CH}_{2} \mathrm{CH}_{2}\right), 1.26$ ppm (overlapped, 90H, $\left.\left(\mathrm{CH}_{2}\right)_{5}\right) ;{ }^{13} \mathrm{C}$ NMR $(125 \mathrm{MHz}$, $\left.\mathrm{CDCl}_{3}, 20^{\circ} \mathrm{C}\right): \delta 152.9,146.3,136.3,135.9,113.7,106.6$, 73.3, 71.8, 71.4, 70.5-70.4, 69.9, 69.0, 58.9, 30.2, 29.629.5, 29.5-29.4, 29.4, 26.0-26.0, $12.2 \mathrm{ppm}$; IR (KBr): $v=$ $3435 \mathrm{~m}(\mathrm{O}-\mathrm{H}), 2924 \mathrm{~s}(\mathrm{C}-\mathrm{H}), 2855 \mathrm{~s}(\mathrm{C}-\mathrm{H}), 1587 \mathrm{~s}(\mathrm{C}=\mathrm{C})$, $1503 \mathrm{~s}(\mathrm{~N}=\mathrm{C}), 1466 \mathrm{~s}, 1436 \mathrm{~s}, 1374 \mathrm{~m}, 1351 \mathrm{~m}, 1332 \mathrm{~m}$, $1301 \mathrm{~m}, 1225 \mathrm{~m}, 1200 \mathrm{~m}, 1116 \mathrm{~s}, 1033 \mathrm{~m} \mathrm{~cm}^{-1}$; MALDITOF-MS (dithranol as a matrix, $m / z$ ): $\left[\mathrm{M}+\mathrm{H}^{+}\right]$calcd for $\mathrm{C}_{189} \mathrm{H}_{345} \mathrm{~N}_{6} \mathrm{Au}_{3} \mathrm{O}_{45}$ : 4011.40; found: 4011.47; Anal. calcd. for $\mathrm{C}_{189} \mathrm{H}_{345} \mathrm{~N}_{6} \mathrm{Au}_{3} \mathrm{O}_{45}$ : C 56.57; $\mathrm{H}$ 8.67; $\mathrm{N}$ 2.09; found: $\mathrm{C}$ 56.30; H 8.85; N 2.11.

\subsection{Synthesis of $\left[\mathrm{Au}_{3} \mathrm{Pz}_{3}\right] /$ silica ${ }_{\text {hex }}$}

Nanocomposites $\left[\mathrm{Au}_{3} \mathrm{Pz}_{3}\right] /$ silica $_{\text {hex }}$ were fabricated by spin-coating method according to our procedure [12,13]. In this case, an acidic aqueous EtOH solution (EtOH, 29.1$87.5 \mathrm{mg}, 0.6-1.8 \mathrm{mmol}$; HCl, $12 \mathrm{M}, 0.15-0.46 \mathrm{mg}, 1.5 \mathrm{x}$ $10^{-3}-4.5 \times 10^{-3} \mathrm{mmol} ; \mathrm{H}_{2} \mathrm{O}, 6 \mathrm{mg}, 0.3 \mathrm{mmol}$ ) of a mixture of $\left[\mathrm{Au}_{3} \mathrm{Pz}_{3}\right]\left(5 \mathrm{mg}, 1.25 \times 10^{-3} \mathrm{mmol}\right)$ and tetrabutoxysilane (TBOS, $24 \mathrm{mg}, 74.9 \times 10^{-3} \mathrm{mmol}$ ) was held for $12 \mathrm{~h}$ at room temperature $\left(\left[\mathrm{Au}_{3} \mathrm{Pz}_{3}\right] /[\mathrm{TBOS}] /[\mathrm{EtOH}] /[\mathrm{HCl}] /\left[\mathrm{H}_{2} \mathrm{O}\right]=\right.$ 1:60:504-1520:1.2-3.7:266), upon which partial oligomerization of silica source to the columnar assembled $\left[\mathrm{Au}_{3} \mathrm{Pz}_{3}\right]$ took place. The resulting viscous solution $(20 \mu \mathrm{L})$ was spin-coated onto a quartz plate at $3000 \mathrm{rpm}$ for $15 \mathrm{~s}$, affording a colorless transparent film (Fig. 1, inset photograph), which was then dried in air for $24 \mathrm{~h}$ at room temperature and additional $12 \mathrm{~h}$ at $40{ }^{\circ} \mathrm{C}$.

\section{RESULTS \& DISCUSSION}

In the sol-gel synthesis of mesoporous silica, selfassembly of $\left[\mathrm{Au}_{3} \mathrm{Pz}_{3}\right]$ containing two $\mathrm{N}$ atoms in the azole ring in an acidic aqueous alcohol solution is one of the importance steps for the formation of the nanocomposites. In fact, we confirmed that acidolysis of $\left[\mathrm{Au}_{3} \mathrm{Pz}_{3}\right]$ in the mixture of $\mathrm{EtOH}, \mathrm{HCl}$, and $\mathrm{H}_{2} \mathrm{O}$ did not take place due to the presence of the emission band centered at $706 \mathrm{~nm}\left(\lambda_{\text {ext }}=\right.$ $276 \mathrm{~nm}$ ), which is characteristic of the metallophilic interaction [13]. For the formation of highly ordered mesoporous silica nanocomposites with a hexagonal structure, we varied the molar ratios of $\mathrm{EtOH}$ to $\mathrm{HCl}$ in the acidic aqueous alcohol solution from 1520:3.7 to 504:1.23 $\left(\left[\mathrm{Au}_{3} \mathrm{Pz}_{3}\right] /[\mathrm{TBOS}]=1: 60\right)$.

When the molar ratio of EtOH to $\mathrm{HCl}$ was 1520 to 3.7, the spin-coated film showed diffraction peaks at $2 \theta=2.18^{\circ}$ and $4.32^{\circ}$, which can be indexed as $d_{100}$ and $d_{200}$, (Fig. 2A, a). This diffraction pattern was almost similar to other samples, when the molar ratios of $\mathrm{EtOH}$ to $\mathrm{HCl}$ were 1520:1.23, 760:1.23, and 504:1.23 (Fig. 2A, b-d). However, the calcination of this silica film sample $([\mathrm{EtOH}] /[\mathrm{HCl}]=1520: 3.7)$ at $450{ }^{\circ} \mathrm{C}$ for $3 \mathrm{~h}$ showed no diffraction peaks (Fig. 2B, a). This result indicates that assynthesized spin-coated film forms a lamellar structure with an interlayer distance of $4.1 \mathrm{~nm}$ (Fig. 2A, a). Even we reduced the concentration of $\mathrm{HCl}$ to three times lowest than previous sample $([\mathrm{EtOH}] /[\mathrm{HCl}]=1520: 1.23)$, the ordered mesoporous silica with a hexagonal geometry cannot be fabricated (Figs. 2A,B, b). Interestingly, at the same concentration of $\mathrm{HCl}$, the diffraction patterns of the calcined sample prepared with half of the concentration of $\mathrm{EtOH}$ compared to the previous sample $([\mathrm{EtOH}] /[\mathrm{HCl}]=$
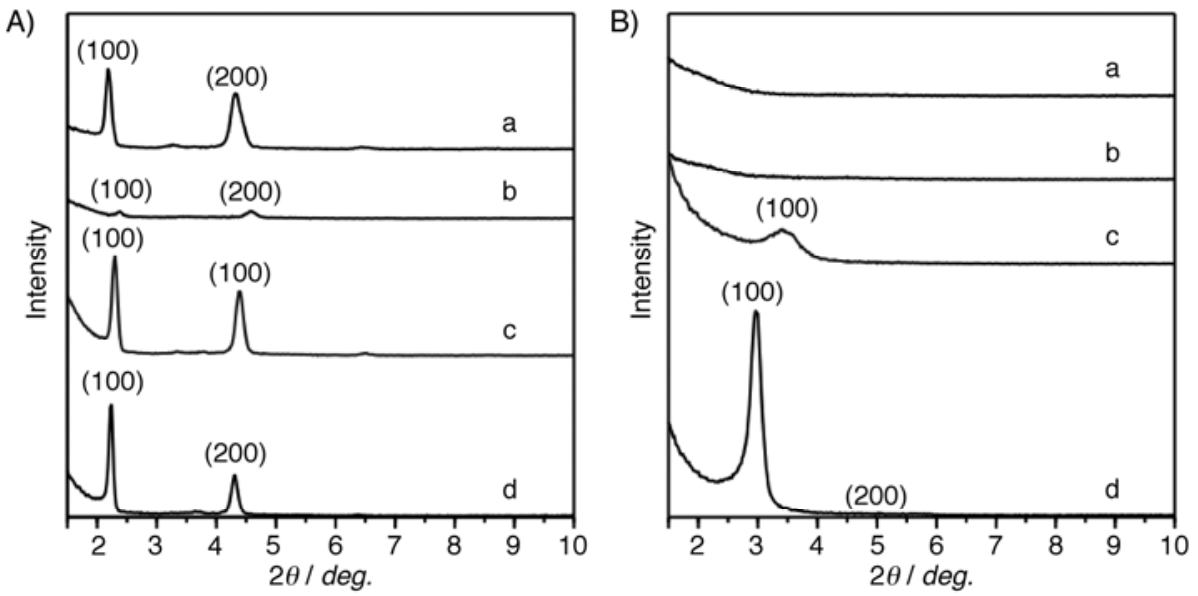

Figure 2: XRD patterns of mesoporous silica film nanocomposites of A) before and B) after calcination prepared with variation of molar ratios of $\mathrm{EtOH}$ to $\mathrm{HCl}$ in the sol-gel synthesis. a) $1520: 3.70$, b) $1520: 1.23$, c) $760: 1.23$, and d) $540: 1.23$. 

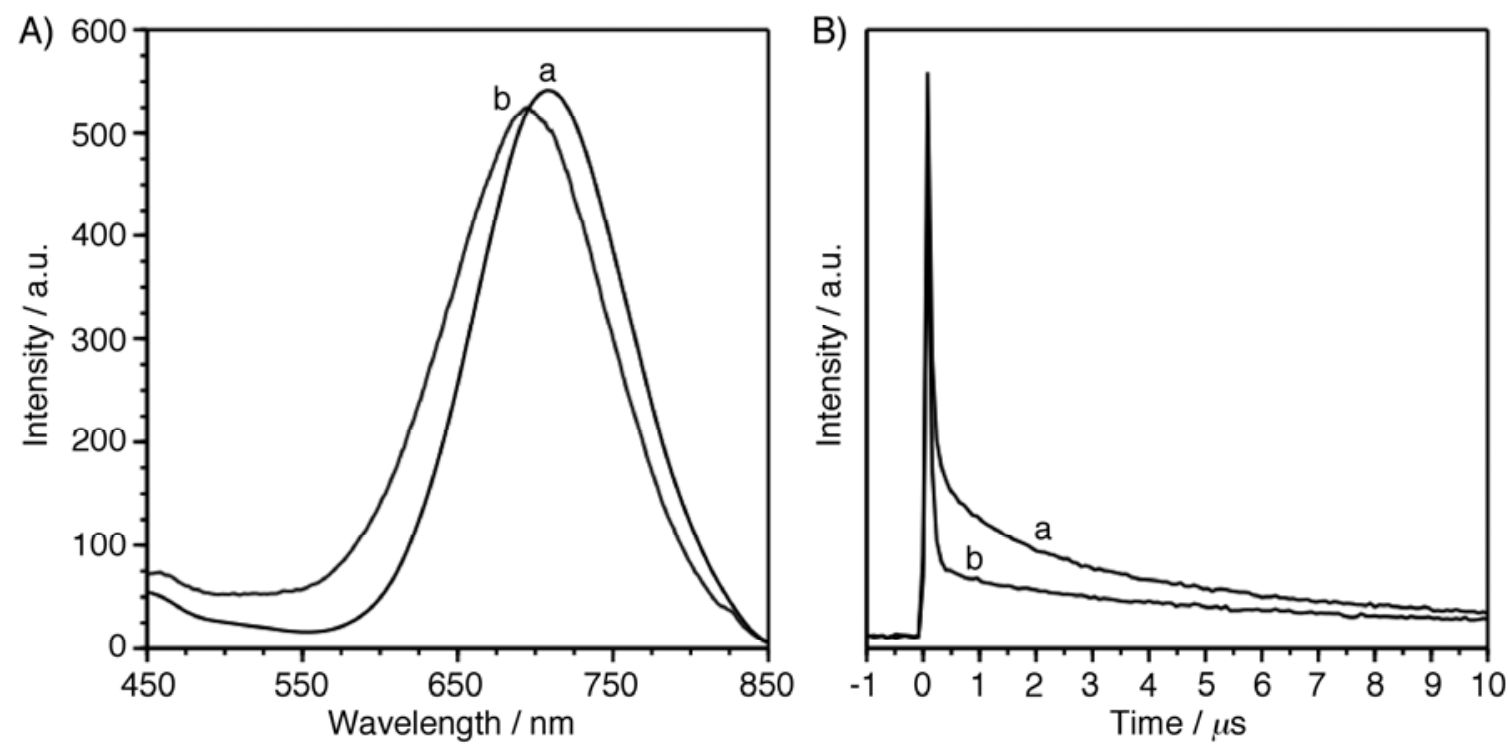

Figure 3: A) Emission spectra $\left(\lambda_{\mathrm{ext}}=276 \mathrm{~nm}\right)$ and B) luminescence decay profiles $\left(\lambda_{\mathrm{ext}}=266 \mathrm{~nm}, \lambda_{\mathrm{em}}=690 \mathrm{~nm}\right)$ of a) $\left[\mathrm{Au}_{3} \mathrm{Pz}_{3}\right] /$ silica ${ }_{\text {hex }}$ and b) bulk $\left[\mathrm{Au}_{3} \mathrm{Pz}_{3}\right]$ (without normalized).

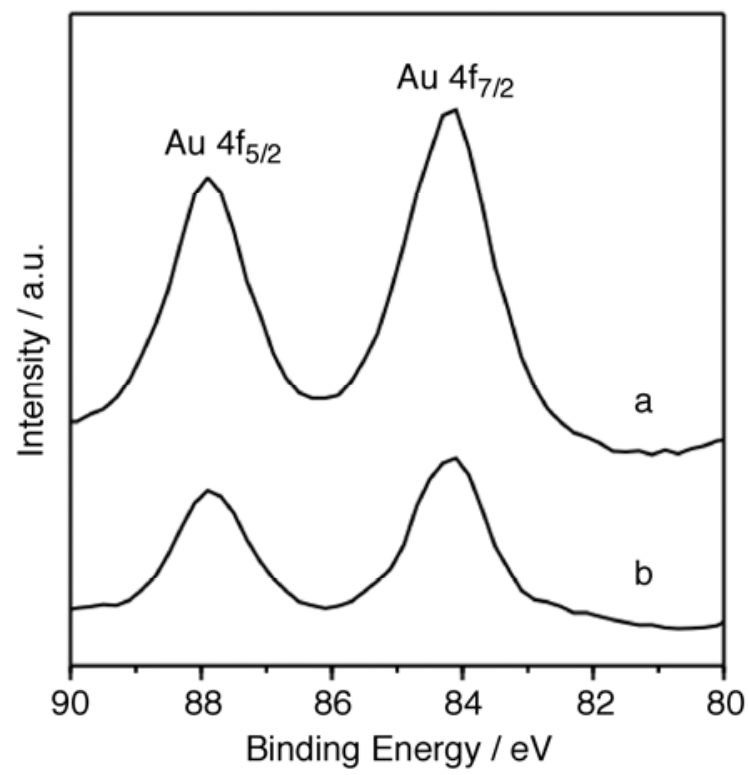

Figure 4: XPS spectra with $\mathrm{Au} 4 \mathrm{f}_{5 / 2}$ and $4 \mathrm{f}_{7 / 2}$ peaks at 84.3 and $88.1 \mathrm{eV}$ of a) $\left[\mathrm{Au}_{3} \mathrm{Pz}_{3}\right] /$ silica $_{\text {hex }}$ and b) bulk [ $\left.\mathrm{Au}_{3} \mathrm{Pz}_{3}\right]$ (without normalized).

760:1.23) showed a little ordered mesoporous silica nanocomposite (Fig. 2B. c). This diffraction peak at $d_{100}$ was intensified drastically (Fig. 2B, d) by decreasing the concentration of $\mathrm{EtOH}$ and $\mathrm{HCl}$ to three times lowest than the first sample $([\mathrm{EtOH}] /[\mathrm{HCl}]=504: 1.23)$. The spincoated film of the last sample showed diffraction peaks at $2 \theta=2.95^{\circ}$ and $5.00^{\circ}$ due to the substantial reduction of the interpore distance from 4.1 to $2.9 \mathrm{~nm}$ (Fig. 2B, d). Because TEM image of the cross-section thin film prepared by an argon ion milling method with a Ion Slicer displayed the hexagonally aligned nanopores [13] and the diffraction patterns preserved the peaks after calcination (Fig. 2B, d), this result strongly indicates the formation of highly ordered mesoporous silica nanocomposite with a hexagonal structure $\left[\mathrm{Au}_{3} \mathrm{Pz}_{3}\right] /$ silica $a_{\text {hex }}$. Therefore, the effect of the molar ratios of $\mathrm{EtOH}$ to $\mathrm{HCl}$ in the acidic aqueous alcohol solution for the self-assembly of $\left[\mathrm{Au}_{3} \mathrm{Pz}_{3}\right]$ with a silica source is one of the most important parameters in the formation of the highly ordered hexagonal silica nanocomposite [12,15].

Upon exposure to $254 \mathrm{~nm}$ UV light with a hand-held lamp in the dark room, the as-fabricated film sample $([\mathrm{EtOH}] /[\mathrm{HCl}]=504: 1.23)$ with highly ordered hexagonal structure emitted in red (Figure 1, inset photograph) with a luminescence center at $693 \mathrm{~nm}$ upon excitation at $276 \mathrm{~nm}$ (Figure 3A, b) with a very large Stokes shift $(\Delta \lambda=417 \mathrm{~nm})$ and luminescence lifetime at $7.8 \mu$ s upon excitation at 266 (Figure 3B, b; $\lambda_{\mathrm{em}}=690 \mathrm{~nm}$ ). Moreover, the luminescence properties of bulk $\left[\mathrm{Au}_{3} \mathrm{Pz}_{3}\right]$ gave the center at $700 \mathrm{~nm}$ (Figure 3A, a) and the lifetimes at $6.3 \mu$ s (Figure 3B, c). 
These luminescence intensities and lifetimes are characteristic of phosphorescing events from metal-centered triple excited state modified with the week $\mathrm{Au}^{\mathrm{I}}-\mathrm{Au}^{\mathrm{I}}$ metallophilic interaction [13]. Moreover, the photochemical properties of $\left[\mathrm{Au}_{3} \mathrm{Pz}_{3}\right]$ are essentially maintained in the hexagonal silica of the nanocomposites. Noteworthy, XPS spectrum of $\left[\mathrm{Au}_{3} \mathrm{Pz}_{3}\right]$ with $\mathrm{Au} 4 \mathrm{f}$ peaks at 84.3 and $88.1 \mathrm{eV}$ (Fig. 4) was almost similar to that of $\left[\mathrm{Au}_{3} \mathrm{Pz}_{3}\right] /$ silica ${ }_{\text {hex }}$ due to the isolation of the complex in the nanoscopic channels of mesoporous silica nanocomposite.

\section{CONCLUSION}

By controlling the molar ratios of $\mathrm{EtOH}$ to $\mathrm{HCl}$ in the acidic aqueous alcohol solution, we highlighted that the template sol-gel synthesis of phosphorescent columnar assembled $\left[\mathrm{Au}_{3} \mathrm{Pz}_{3}\right]$ with a silica source can provide highly ordered mesoporous silica film nanocomposite with a hexagonal structures. Development of optical chemosensors using these mesoporous silica would be worthy of further investigation due to phosphorescent properties of the complex and physical properties of hexagonal silica nanocomposites.

\section{ACKNOWLEDGEMENT}

The present work was supported by the Ministry of Education, Science, Sport, and Culture, Japan. The authors thank Prof. Takashi Yamashita, Tokyo University of Science, Japan for luminescence lifetimes measurement using transient emission flash photolysis of the mesoporous silica film nanocomposites. H. O. Lintang thanks Ministry of Education, Science, Sport, and Culture, Japan for the financial support via Monbukagakusho Scholarship to study this research in the Master and Doctoral program at Department of Chemistry and Biotechnology, School of Engineering, The University of Tokyo, Japan.

\section{REFERENCES}

[1] C. Sanchez, G. J. de A. A. Soler-Illia, F. Ribot, T. Lalot, C. R. Mayer, and V. Cabuil, Chem. Mater., 13 (2001), $3061-3083$.

[2] G. A. Ozin, Adv. Mater., 4 (1992) 612-649.

[3] F. Hoffmann, M. Cornelius, J. Morell, and M. Fröba, Angew. Chem. Int. Ed., 45 (2006) 3216-3251.

[4] T. Aida and K. Tajima, Angew. Chem. Int. Ed., 40 (2001), 3803-3806.

[5] Y. Lu, Y. Yang, A. Sellinger, M. Lu, J. Huang, H. Fan, R. Haddad, G. Lopez, A. R. Burns, D. Y. Sasaki, J. Shelnutt, and C.J. Brinker, Nature, 410 (2001), 913-917.

[6] M. Ikegame, K. Tajima, and T. Aida, Angew. Chem. Int. Ed., 42 (2003), 2154-2157.

[7] G. Li, S. Bhosale, T. Wang, Y. Zhang, H. Zhu, and J.-H. Fuhrhop, Angew. Chem. Int. Ed., 42 (2003), $3818-3821$.

[8] A. P.-Z. Clark, K.-F. Shen, Y. F. Rubin, and S. H. Tolbert, Nano Lett., 5 (2005) 1647-1652.

[9] A. Okabe, T. Fukushima, K. Ariga, and T. Aida, Angew. Chem. Int. Ed., 41 (2002), 3414-3417.

[10] M. Kimura, K. Wada, K. Ohta, K. Hanabusa, H. Shirai, and N. Kobayashi, J. Am. Chem. Soc., 123 (2001), $2438-2439$.

[11] A. Okabe, M. Niki, T. Fukushima, K. Ariga, and T. Aida, Chem. Commun., (2004), 2572-2573.

[12] W. Otani, K. Kinbara, and T. Aida, Faraday. Discuss., 143 (2009), 335-343.

[13] H. O. Lintang, K. Kinbara, K. Tanaka, T. Yamashita, and T. Aida, Angew. Chem. Int. Ed., 49 (2010), $4241-4245$.

[14] H. O. Lintang, K. Kinbara, K. Tanaka, T. Yamashita, and T. Aida, in: 2010 International Conference on Enabling Science and Nanotechnology, ESciNano, ISBN: 978-1-4244-8854-4 (IEEE), Proceedings (2010), Article number 5700970.

[15] Xiu S. Zhao, G. Q. M. Lu, and G. J. Millar, Ind. Eng. Chem. Res., 35 (1996), 2075-2090. 